\section{PhYSICAL ACTIVITY LEVEL AND HYPOGLYCEMIA IN TYPE 1 DIABETES PATIENTS}

\author{
Camila Kümmel Duarte ${ }^{1}$, Ticiana da Costa Rodrigues ${ }^{1,2}$, \\ Aline Juliana Schneider Merker ${ }^{1}$, Fabiane de Oliveira Brauner ${ }^{1}$, \\ Jussara Carnevale de Almeida ${ }^{1,2}$
}

\begin{abstract}
Introduction: The recommended management for individuals with type 1 diabetes (T1D) includes an intensive treatment with insulin therapy and the practice of regular exercise. However, this association is related with hypoglycemia episodes.

Objective: The aim of this study was to perform a cross-sectional evaluation of the association between the physical activity (PA) level and hypoglycemia episodes reported in patients with T1D.
\end{abstract}

Methods: Adult outpatients with T1D had their PA level assessed by the International Physical Activity Questionnaire (long form), considering the intensity of the physical activity (vigorous, moderate and/or walks) in daily activities, such as at work, means of transport, domestic activities and at leisure, and answered questions about self-care and hypoglycemia episodes.

Results: The study included 126 patients who presented the following characteristics: mean age of $35(28-47)$ years old and $16(11-24)$ years of diabetes duration, $55 \%$ women, $\mathrm{HbA} 1 \mathrm{c}=9.3 \pm 2.1 \%$, and body mass index $=25.0 \pm 4.2 \mathrm{~kg} / \mathrm{m}^{2}$. Very active patients had lower values of glucose and LDL-cholesterol when compared with the less active group. A greater proportion of active (48.1\%) and very active patients $(66.7 \%)$ reported practicing exercise regularly when compared with the less active subjects $(13.3 \% ; P=0.003)$. Less active patients had a three-fold chance of reporting hypoglycemia episodes when compared with very active patients (OR=3.49; $\mathrm{Cl} 95 \%$ : 1.26-9.70; $P=0.016)$.

Conclusions: Less active adults with T1D presented more hypoglycemia, probably due to the practice of informal moderate and/or vigorous activities without specific self-care.

Keywords: Exercise; self-care; blood glucose

Diabetes Mellitus (DM) is a metabolic disease characterized by hyperglycemia, resulting from defects in insulin action and/or secretion ${ }^{1}$. In Brazil, the prevalence of self-reported DM in the adult urban population is $6.3 \%{ }^{2}$. Among the types of DM, type $1 \mathrm{DM}$ (T1D) accounts for $10 \%$ of the cases in the population in general $^{3}$. The treatment of individuals with T1D uses exogenous insulin, a healthy diet with carbohydrates from vegetables, fruits, whole grains, legumes and milk, besides frequently practicing, regular moderate-intensity aerobic exercise for at least 150 minutes a week ${ }^{1,4}$.

Regular exercise improves cardiovascular performance, insulin sensitivity, and creates a feeling of well-being. Furthermore, the terms regular exercise and physical activity (PA) are often used synonymously, although they are not synonyms. PA is considered every bodily movement produced by the skeletal musculature, and that results in a greater expenditure of energy than the levels of rest ${ }^{5}$ and it also presents biopsychosocial, cultural and behavioral components $^{6}$. On the other hand, regular exercise is considered any PA that
Clin Biomed Res. 2016;36(2):59-65

1 Endocrine Division, Hospital de Clínicas de Porto Alegre, Universidade Federal do Rio Grande do Sul (UFRGS). Porto Alegre, Rio Grande do Sul, Brazil.

2 Department of Internal Medicine, Faculdade de Medicina, Universidade Federal do Rio Grande do Sul (UFRGS). Porto Alegre, Rio Grande do Sul, Brazil.

Corresponding author: Jussara Carnevale de Almeida jcalmeida@hcpa.edu.br Endocrine Division, Hospital de Clínicas de Porto Alegre

Rua Ramiro Barcelos, 2350.

90035-903, Porto Alegre, RS, Brazil. 
has been planned, systematized, structured and is repetitive, aiming to improve and maintain physical aptitude ${ }^{5}$.

Globally, around $23 \%$ of adults aged 18 and over were insufficiently active in 2010 (men 20\% and women $27 \%)^{7}$. In the VIGITEL study a prevalence of $60 \%$ of reported inactivity was observed in the Brazilians' leisure schedules ${ }^{8}$. One study evaluated the level of PA in individuals with DM, and observed that T1DM patients were classified as active and very active, and reported that they practiced more regular exercise than the patients with $\mathrm{T}^{2} \mathrm{D}^{9}$, possibly because they were younger. Similar results were found in other populations ${ }^{10,11}$.

Intensive treatment reduces the incidence of chronic microvascular complications in patients with $\mathrm{DM}^{12}$, but it is associated with an increase in the number of hypoglycemic episodes ${ }^{13,14}$. In addition, patients with T1D report more hypoglycemia episodes than patients with $\mathrm{T}^{2} \mathrm{D}^{9}$, possibly due to the association of the use of insulin with the practice of PA. Studies of prospective cases suggest that hypoglycemia can be prevented by education of patients with T1D for self-care ${ }^{15,16}$, In this sense, the present study aims to evaluate the possible association between the PA level and the report of moderate and /or severe episodes of hypoglycemia in the last six months in a group of T1D patients, and also to evaluate the self-care measures performed regarding regular exercise practice.

\section{METHODS}

\section{Patients}

This is a cross-sectional study conducted in patients with T1D and aged over 18 years, consecutively followed at the Diabetes Outpatient Clinic in the Endocrine division at Hospital de Clínicas de Porto Alegre (HCPA). For the diagnosis of type of DM, the criteria of the World Health Organization (1985) were considered: diagnosis before the age of 30 years, need for insulin in the first year after diagnosis, and/or presence of diabetic ketoacidosis or tendency to ketosis. The patients considered eligible to participate in the study after signing the free and informed consent were submitted to evaluation of the clinical history, physical examination, including measuring blood pressure and anthropometric measurements, laboratory evaluation and answering the International Physical Activity Questionnaire (IPAQ), besides questions referring to hypoglycemia episodes and self-care related to the practice of regular exercise. This study was conducted according to the guidelines laid down in the Declaration of Helsinki and all procedures involving patients were approved by the
Institutional Review Board. Written informed consent was obtained from all patients.

\section{Methods}

Patients underwent clinical evaluation as previously described ${ }^{17}$. Body weight and height of patients (without shoes or coats) were obtained with measurements recorded to the nearest $100 \mathrm{~g}$ for weight and to the nearest $0.1 \mathrm{~cm}$ for height. Body mass index (BMI) $\left(\mathrm{kg} / \mathrm{m}^{2}\right)$ was calculated.

PA level was measured using the Brazilian Portuguese validated version of the International Physical Activity Questionnaire proposed by the WHO, long and self-applicable version ${ }^{18}$. We analyzed the intensity (walk, moderate or vigorous activity), time of duration of the PA performed, and if it was performed during work, as means of transport, in domestic activities such as in the garden or in the house, and at leisure according to the PA level evaluated by IPAQ. The patients were classified in four categories according to the reported PA practice in a typical week: Very active $=$ performing at least 30 minutes of vigorous activities on more than five days a week or at least 20 minutes of vigorous activities on three or more days a week associated with at least 30 minutes of moderate activities and/or walks on five or more days a week; Active = performing at least 20 minutes of vigorous activities on more than three days a week or at least thirty minutes of moderate activities/walks on five or more days a week or any activity that adds up to 150 minutes divided into at least five days a week; Irregularly active = a person who has not reached any of the criteria of the recommendation (frequency and/or duration); Sedentary = the patient who has not performed any physical activity for at least 10 minutes continuously. To present the results, the classifications of "sedentary" and "irregularly active", were grouped under the term "less active". Active and very active patients were considered "performers" of regular PA. The patients were also asked about regular practice of exercise, type of activity performed, duration and weekly frequency. The people who practiced regular exercise were also investigated about prior knowledge and performance of self-care actions related to the practice of regular exercise (food, insulin use, and monitoring capillary blood glucose).

In order to evaluate hypoglycemia, non-validated questions were formulated based on the Clarke Score ${ }^{19}$ questionnaire: capacity to recognize the symptoms during non-confirmed hypoglycemia, number of episodes of moderate and/or severe non-confirmed hypoglycemia in the last six months, besides the report of non-confirmed hypoglycemia episodes (symptomatic and/or asymptomatic) related to the 
practice of moderate and vigorous exercise or $\mathrm{PA}$, at the same time as the PA questionnaire was applied. Asymptomatic hypoglycemia was defined as blood glucose values $<3.9 \mathrm{mmol} . \mathrm{L}^{-1}$ with no symptoms. Moderate hypoglycemia was defined as an episode in which a patient felt confuse, adrift, slow and could not revert its hypoglycemia alone. A severe hypoglycemia was defined as an episode of hypoglycemia in which a patient required assistance from another person and needed glucagon or glucose injection ${ }^{19}$.

Blood samples were collected after a 12-h fast. Plasma glucose was measured by the glucose oxidase method, glycated hemoglobin (HbA1c) by an ion-exchange HPLC procedure using a reference range of $4 \cdot 8-6 \%{ }^{20}$, total cholesterol and triacylglycerol by specific enzymatic colorimetric methods and HDL-cholesterol by the homogeneous direct method. LDL-cholesterol was estimated using the Friedewald formula when triacylglycerol values $<4.5 \mathrm{mmol} / \mathrm{L}^{21}$. All tests were performed at the Hospital de Clínicas de Porto Alegre Clinical Pathology Laboratory.

\section{Statistical Analysis}

For analysis the patients were grouped according to the classification of the PA level into three groups: less active, active or very active, based on the IPAQ classification. The data are described as mean \pm standard deviation, median (interquartile interval), or number of cases for the total number of patients of the group (\%). To compare the groups of patients, the ANOVA test and Kruskal-Wallis were applied for independent samples, or Chi-square, as described. $\mathrm{P}$ values $<0.05$ (two-sided) were considered as statistically significant. All analyses were performed using PASW 18.0 (SPSS, Inc.).

\section{RESULTS}

The study included 126 adults with T1D seen at the Endocrine Outpatient Clinic of HCPA during the period from October 2008 to March 2010 (age: $37.1 \pm 11.0$ years old; diabetes duration: $16(11-24)$ years; BMI: $25.0 \pm 4.2 \mathrm{Kg} / \mathrm{m}^{2}$; male: $44.4 \%$ ). The clinical, anthropometric, and laboratory characteristics according to the three levels of PA are shown in Table 1. A total of 15 patients $(11.9 \%)$ were classified as less active, 81 patients $(64.3 \%)$ as active, and 30 patients $(23.8 \%)$ as very active. The very active patients presented lower values of LDL-cholesterol compared to less active patients $(P=0.011)$, but without a statistical difference compared to the group of active patients $(P=0.913)$. As to the HDL-cholesterol values, only the active patients presented higher values compared to the two groups of PA extremes, but with a borderline significance [very active and not very active; $P=0.055$ ].

The individuals classified as very active reported that they did more vigorous and moderate PA compared to active and less active patients as shown on Table 2. The frequency of reports of asymptomatic and symptomatic hypoglycemia in the last six months of evolution, and the presence of symptoms of hypoglycemia during PA are shown in Figure 1.

Table 1: Clinical characteristics, lifestyle, and laboratory characteristics of insulin-dependent type 1 diabetes mellitus patients, grouped according to the level of physical activity $(n=126)$.

\begin{tabular}{lccrc}
\hline & Less active & Active & Very Active & P \\
\hline $\mathbf{N}$ & 15 & 81 & 30 & - \\
Age (years) & $40.9 \pm 11.4$ & $37.3 \pm 11.0$ & $34.4 \pm 10.5$ & $0.166^{1}$ \\
Diabetes duration (years) & $19(14-26)$ & $16(11-21)$ & $18.5(13-25)$ & $0.560^{3}$ \\
Males & $8(53.3 \%)$ & $30(37.0 \%)$ & $18(60.0 \%)$ & $0.074^{2}$ \\
Whites & $12(80.0 \%)$ & $69(85.2 \%)$ & $28(93.3 \%)$ & $0.394^{2}$ \\
Current smokers & $3(20 \%)$ & $11(13.6 \%)$ & $2(6.7 \%)$ & $0.462^{2}$ \\
Alcoholic beverage intake (previous month) & $3(20 \%)$ & $19(23.5 \%)$ & $12(40 \%)$ & $0.177^{2}$ \\
Insulin therapy (IU) & $52.1 \pm 18.2$ & $46.9 \pm 19.3$ & $44.9 \pm 15.7$ & $0.259^{1}$ \\
Dietary counseling by registered nutritionist & $8(53.3 \%)$ & $37(45.7 \%)$ & $18(63 \%)$ & $0.392^{2}$ \\
Diet adherence (occasionally and/or always) & $12(80.0 \%)$ & $60(74.0 \%)$ & $26\left(86 . \%^{2}\right)$ & $0.213^{2}$ \\
Fasting blood glucose (mmol/L) & $12.8(6.7-17.2)$ & $10.2(7.0-16.2)$ & $7.1(4.6-12.0)^{\mathrm{a}}$ & $0.020^{3}$ \\
HbA1c (\%) & $9.6 \pm 2.0$ & $9.5 \pm 2.2$ & $8.6 \pm 1.6$ & $0.108^{1}$ \\
Total cholesterol (mmol/L) & $10.4 \pm 2.55$ & $10.1 \pm 2.3$ & $9.9 \pm 2.7$ & $0.793^{1}$ \\
HDL cholesterol (mmol/L) & $2.8 \pm 0.5^{\mathrm{b}}$ & $3.4 \pm 0.9^{\mathrm{b}}$ & $3.1 \pm 0.8$ & $0.052^{1}$ \\
LDL cholesterol (mmol/L) & $7.2 \pm 1.6^{\mathrm{c}}$ & $5.4 \pm 1.8$ & $5.5 \pm 2.1$ & $0.036^{1}$ \\
Triacylglycerols (mmol/L) & $5.2(3.9-6.5)$ & $4.5(3.3-6.9)$ & $4.7(3.3-2.5)$ & $0.785^{3}$ \\
\hline
\end{tabular}

Data presented as mean \pm standard deviation; median (interquartile interval) or number for total of patients in group (\%). ${ }^{1}$ ANOVA

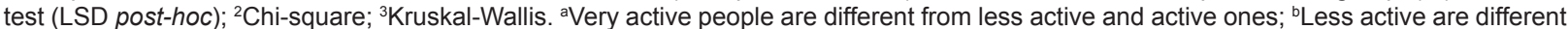
from the active ones; 'Less active are different from active and very active patients. 
Table 2: Median metabolic equivalents performed by patients in each domain of physical activity grouped according to the level of physical activity $(n=126)$.

\begin{tabular}{|c|c|c|c|c|}
\hline \multirow[b]{2}{*}{$\begin{array}{l}\text { Metabolic equivalents } \\
\text { (METs - minutes/week) }\end{array}$} & \multicolumn{3}{|c|}{ Physical activity level } & \multirow[b]{2}{*}{$\mathbf{P}$} \\
\hline & $\begin{array}{l}\text { Less active } \\
\qquad(n=15)\end{array}$ & $\begin{array}{l}\text { Active } \\
(n=81)\end{array}$ & $\begin{array}{l}\text { Very active } \\
\quad(n=30)\end{array}$ & \\
\hline Vigorous PA during work & $0(0-0)$ & $0(0-0)$ & $720(0-5,040)$ & 0.01 \\
\hline Vigorous PA in leisure activities & $0(0-0)$ & $0(0-0)$ & $240(0-1,920)$ & 0.01 \\
\hline Moderate PA during work & $0(0-0)$ & $0(0-1,470)$ & $180(0-4,440)$ & 0.04 \\
\hline Moderate PA in the garden & $0(0-0)$ & $80(0-600)$ & $360(0-1,260)$ & 0.01 \\
\hline Moderate PA in the house & $0(0-0)$ & $810(285-2,700)$ & $615(90-2,160)$ & 0.01 \\
\hline Walking during work & $0(0-445)$ & $0(0-445)$ & $495(0-1,930.5)$ & 0.01 \\
\hline Walking as mean of transportation & $0(0-495)$ & $247.5(66-478.5)$ & $577.5(0-1,188)$ & 0.04 \\
\hline
\end{tabular}

Data presented as median (interquartile interval) in minutes/week. Kruskal-Wallis. PA: Physical activity.

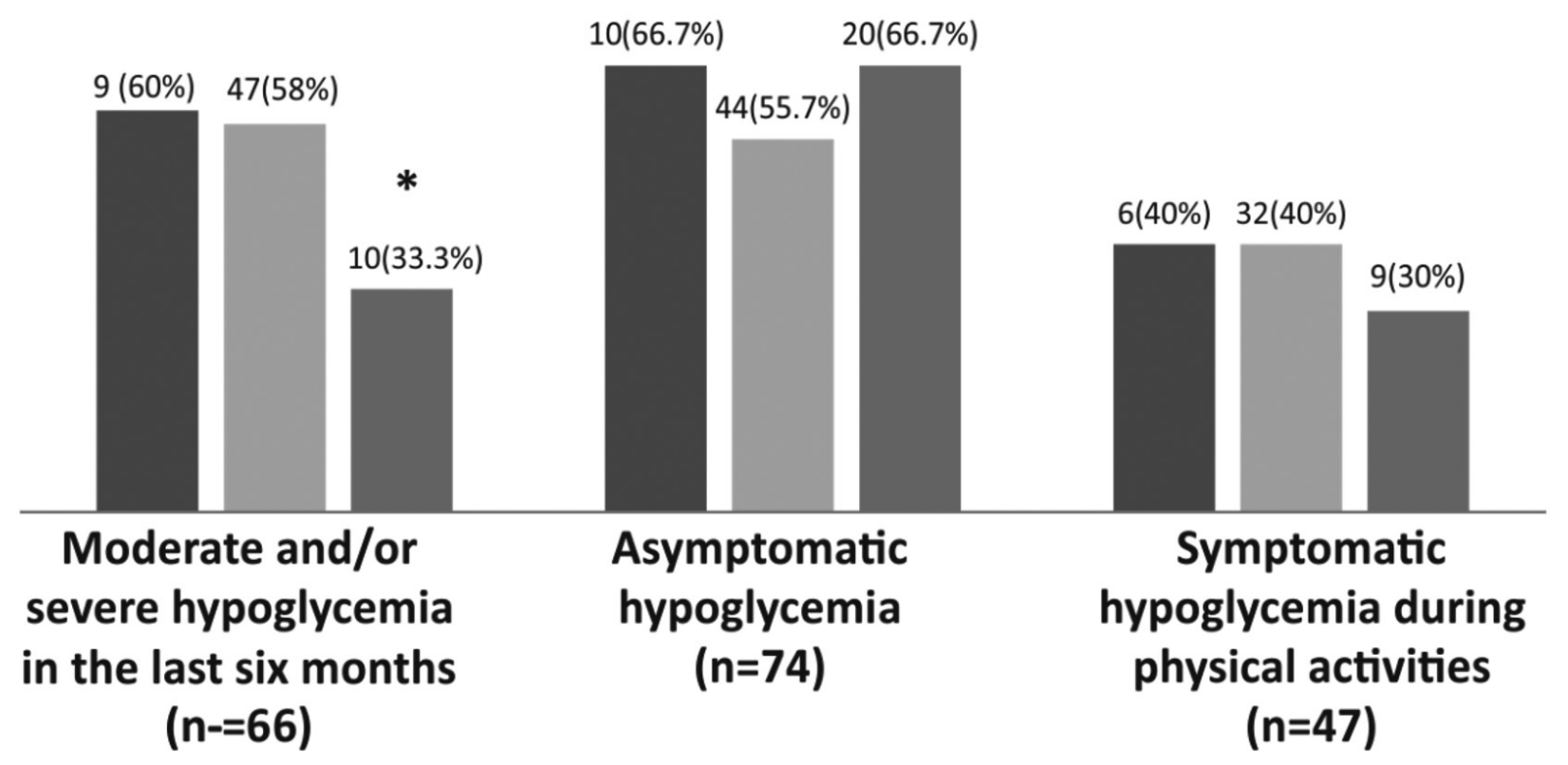

Sedentary or irregularly active

Active

Very Active

Figure 1: Frequency of hypoglycemia report in patients with type 1 Diabetes Mellitus according to Physical Activity Level proposed by the long version of the International Physical Activity Questionnaire $(n=126)$. $P=0.056$ (Chi-square test).

A greater proportion of active patients (48.1\%) and very active patients $(66.7 \%)$ reported that they practiced exercise regularly compared to the less active group (13.3\%; $p=0.003)$. When we analyzed the frequency of programed regular exercise of the patients, only 61 patients $(48.4 \%)$ reported that they practiced regularly. Also, 22 of the 61 patients reported that they received specific orientation about self-care (insulin, diet, capillary blood glucose monitoring) to practice regular exercise, and that these orientations were given by a physician to $36.4 \%$ of the patients, by a registered nutritionist to $45.4 \%$ of the patients, and by both professionals to $13.6 \%$ of the patients. One patient reported having received guidance from another health care professional. The proportion of patients who reported receiving specific guidance for the practice of regular exercise was not different among the patients with or without complaints of episodes of hypoglycemia in regular exercise: $9(40.9 \%)$ vs. $13(59.1 \%) ; p=0.792$.

Of the 61 patients who practice exercise regularly, only 28 patients reported taking some kind of care before, during or after regular exercise. The most cited results were careful with food $(25 \%)$, followed 
by being careful with food associated with monitoring of the capillary blood glucose $(21.4 \%)$. Besides, care with stretching and/or warm ups $(10.7 \%)$, only stretching $(17.9 \%)$, monitoring capillary blood glucose alone (14.3\%), monitoring associated with stretching $(3.6 \%)$, presence of prior symptoms $(3.6 \%)$, stretching associated with food $(3.6 \%)$ were also reported.

Multiple regression models was performed with at least one report of moderate and/or severe hypoglycemia in the last six months as dependent variable and PA level as independent variable adjusted for variables of biological importance, such as blood glucose values and report of following diet. The less active patients presented three times more chance of reporting episodes of hypoglycemia compared to very active patients (OR=3.49; $\mathrm{Cl} 95 \%$ 1.26-9.70; $p=0.016$ ). There were no differences between very active patients vs. active patients and between less active and active patients.

\section{DISCUSSION}

In the present study, less active patients with T1D had a three-fold greater chance of reporting episodes of hypoglycemia compared to very active patients. The patients were classified by IPAQ as active and very active, mainly by the moderate and vigorous PA performed in the work environment and the walks to get around (as a means of transport).

No Brazilian studies were found to evaluate the PA level and its relationship with hypoglycemia in patients with T1D, only studies conducted with young Finns ${ }^{22}$ and Italians ${ }^{11}$. The heterogeneity between international ${ }^{10,11,22-24}$ and national studies ${ }^{25}$ is also outstanding regarding the methods used to evaluate the PA level of populations, making it difficult to have an adequate comparison between the existing evidence. The evaluation of PA level by IPAQ in different populations worldwide has been suggested by the World Health Organization since 2001 , precisely to allow comparisons between the populations ${ }^{26}$.

The less active patients presented a three-fold greater chance of reporting hypoglycemia compared to the very active patients. Patients that are more active are probably those that are more compliant with all other issues concerning diabetes self-care. Taking into account that regular exercise improves sensitivity to the action of insulin ${ }^{27}$, possibly the less active individuals do not know the reaction of their own metabolism to PA, and they did not practice enough exercise to have the benefit in the metabolic control. The ADA recommend that adults with diabetes should be advised to perform at least 150 minutes/week of moderate-intensity aerobic physical activity (50-70\% of maximum heart rate), spread over at least 3 days/week with no more than 2 consecutive days without exercise ${ }^{4}$. There are also considerable data for the health benefits (e.g., increased cardiovascular fitness, muscle strength, improved insulin sensitivity, etc.) of regular exercise for those with type 1 diabetes $^{4}$. On the other hand, good fitness level individuals tend to exercise at greater work thresholds and present better insulin sensitivity, which have been already associated with exercise-associated hypoglycemia in patients with Type 1 diabetes ${ }^{28}$. The strategies to prevent episodes of hypoglycemia related to the practice of PA recommended by the $\mathrm{ADA}^{1}$ are self-monitoring of blood glucose before, during and after regular exercise to adjust the diet and insulin doses used habitually. In this study, care with food was the most prevalent self-care behavior among the patients who practiced regular exercise, followed by the association of care with food and capillary blood glucose. The regular practice of exercise allows a better management of this issue by the patient with diabetes guided by their health team, since the factors that have been related to the glycemic response during the regular exercise are: the metabolic control of the patient itself, the type and intensity of the activity performed, the amount of insulin applied before the regular exercise, the time when exercise is done, besides the phase of the menstrual cycle in women ${ }^{29}$. Further, a cross-sectional study of 103 patients with T1D observed that one of the main causes that prevent the practice of regular exercise was the fear that hypoglycemia episodes would occur ${ }^{29}$.

Patients who were less active presented higher values of plasma glucose and LDL cholesterol compared to very active patients. However, since Hba1c was similar among groups, this could be caused by chance. Some authors ${ }^{11,22}$ observed a better glycemic control in more active patients. Patients with T1D who irregularly practiced 60 minutes of PA a week ${ }^{11}$, or patients classified as sedentary ${ }^{22}$, presented worse glycemic control (evaluated by $\mathrm{HbA1c}$ ), when compared to the more active patients. In fact, lifestyle modifications - healthy diet and regular practice of PA - associated with the regular use of insulin are recommendations to obtain and maintain a better metabolic control of $\mathrm{DM}^{6}$. The practice of regular exercise improves glycemic control and the lipid profile in individuals with and without $\mathrm{DM}^{30,31}$.

The active and very active patients in this study were classified thus due to the PA performed during work and as a means of transportation and not by regular exercise. Similar results were observed by other authors in cross-sectional studies with patients without $\mathrm{DM}^{32,33}$. Regarding this, a more comprehensive 
evaluation of the PA level seems to be important for the health professional team in order to advise on self-care during routine physical activity, and not only in formal exercise.

Limitations inherent to the instrument used to evaluate the PA level, sample size, and evaluation of the outcome (hypoglycemia) of the reports and not from capillary measurements needs to be considered in the preliminary analysis of the results presented. However, the use of self-reported hypoglycemia is a conservative bias, since the patients may have autonomous neuropathy and not perceive the hypoglycemia associated or not with the practice of PA.

Based on the presented results, patients with T1D were classified mostly as active, but due to the practice of moderate and/or vigorous PA during work and as a mean of transport, and not due to the practice of regular exercise. The very active T1D patients may have three times less chance of reporting episodes of hypoglycemia compared to the T1D who exercise less or do it irregularly. And only one-third of those who practiced regular exercise, independent of the level of PA by IPAQ, perform self-care measures for the prevention of PA-related hypoglycemia. These findings show that the T1D patients need special attention and better information from their health professionals about PA and hypoglycemia prevention.

\section{Acknowledgements}

The present study was supported by grants from FIPE - Hospital de Clínicas de Porto Alegre, Brazil. The authors' contributions were as follows: A.J.S.M., J.C.A. and T.C.R. designed the research; C.K.D., A.J.S.M., F.O.B. performed the data collection; C.K.D. and J.C.A. performed the statistical analyses and wrote the paper; C.K.D., J.C.A and T.C.R. had primary responsibility for the final content; All authors approved the final version of the paper. None of the authors had a personal or financial conflict of interest.

\section{REFERENCES}

1. Evert AB, Boucher JL, Cypress M, Dunbar SA, Franz MJ, MayerDavis EJ, et al. Nutrition therapy recommendations for the management of adults with diabetes. Diabetes Care. 2014;37(Suppl 1):S120-43. http://dx.doi.org/10.2337/dc14-S120. PMid:24357208.

2. Iser BP, Malta DC, Duncan BB, de Moura L, Vigo A, Schmidt MI. Prevalence, correlates, and description of self-reported diabetes in brazilian capitals - results from a telephone survey. PLoS One. 2014;9(9):e108044. http://dx.doi. org/10.1371/journal.pone.0108044. PMid:25255096.

3. Halimi S, Benhamou PY. [Diabetes, a worldwide disease]. Presse Med. 2004;33(Spec No):Sp37-40. PMid:15360144.

4. Standards of medical care in diabetes. Diabetes Care. 2016;39(Suppl. 1):S45. PMid:26696680.

5. Caspersen CJ, Powell KE, Christenson GM. Physical activity, exercise, and physical fitness: definitions and distinctions for healthrelated research. Public Health Rep. 1985;100(2):126-31. PMid:3920711.

6. Pitanga FJ. Epidemiologia, atividade física e saúde. Rev Bras Cien e Mov. 2002;10:49-54
7. World Health Organization (WHO). Global status report on noncommunicable diseases 2014 [online]. 2014 [cited 2016 Jan 26]. Available from: http://apps.who.int/iris/ bitstream/10665/148114/1/9789241564854 eng.pdf?ua $=1$

8. Schmidt MI, Duncan BB, Hoffmann JF, Moura L, Malta DC, Carvalho RM. Prevalence of diabetes and hypertension based on self-reported morbidity survey, Brazil, 2006. Rev Saude Publica. 2009;43(Suppl 2):74-82. http://dx.doi.org/10.1590/ S0034-89102009000900010. PMid:19936501.

9. Duarte CK, Almeida JC, Merker AJ, Brauer FO, Rodrigues TC. Physical activity level and exercise in patients with diabetes mellitus. Rev Assoc Med Bras. 2012;58(2):215-21. PMid:22569617.

10. Bishop FK, Maahs DM, SnellBergeon JK, Ogden LG, Kinney GL, Rewers M. Lifestyle risk factors for atherosclerosis in adults with type 1 diabetes. Diab Vasc Dis Res. 2009;6(4):269-75. http://dx.doi. org/10.1177/1479164109346359. PMid:20368221.

11. Bernardini AL, Vanelli M, Chiari G, lovane B, Gelmetti C, Vitale R, et al. Adherence to physical activity in young people with type 1 diabetes.
Acta Biomed. 2004;75(3):153-7. PMid:15796088.

12. Cryer PE. Hypoglycaemia: the limiting factor in the glycaemic management of Type I and Type II diabetes. Diabetologia. 2002;45(7):937-48. http://dx.doi.org/10.1007/s00125-0020822-9. PMid:12136392.

13. The Diabetes Control and Complications Trial Research Group. The effect of intensive treatment of diabetes on the development and progression of long-term complications in insulin-dependent diabetes mellitus. $N$ Engl J Med. 1993;329(14):977-86. http://dx.doi. org/10.1056/NEJM199309303291401. PMid:8366922.

14. Hypoglycemia in the Diabetes Control and Complications Trial. The Diabetes Control and Complications Trial Research Group. Diabetes. 1997;46(2):271-86. http://dx.doi. org/10.2337/diab.46.2.271. PMid:9000705.

15. Lemozy-Cadroy S, Crognier $S$, Gourdy P, Chaauchard MC, Chale JP, Tauber Dagger JP, et al. Intensified treatement of type 1 diabetes: prospective evaluation at one year of therapeutic patient education programme. Diabetes Metab. 2002;28(4 Pt 1):287-94. PMid:12442066. 
16. Sämann A, Mühlhauser I, Bender R, Kloos C, Müller UA. Glycaemic control and severe hypoglycaemia following training in flexible, intensive insulin therapy to enable dietary freedom in people with type 1 diabetes: a prospective implementation study. Diabetologia. 2005;48(10):1965-70. http://dx.doi.org/10.1007/s00125-0051905-1. PMid:16132954.

17. Rodrigues TC, Pecis M, Canani LH, Schreiner L, Kramer CK, Biavatti $\mathrm{K}$, et al. [Characterization of patients with type 1 diabetes mellitus in southern Brazil: chronic complications and associated factors]. Rev Assoc Med Bras. 2010;56(1):6773. http://dx.doi.org/10.1590/ S0104-42302010000100019. PMid:20339790.

18. World Health Organization (WHO). International Physical Activity Questionnaire (IPAQ) [online]. 1998 [cited 2016 May 31]. Available from: http://www.celafiscs.org.br/index.php/ contribuicoes-a-ciencia

19. Clarke WL, Cox DJ, Gonder-Frederick LA, Julian D, Schlundt D, Polonsky W. Reduced awareness of hypoglycemia in adults with IDDM. A prospective study of hypoglycemic frequency and associated symptoms. Diabetes Care. 1995;18(4):517-22. http:// dx.doi.org/10.2337/diacare.18.4.517. PMid:7497862.

20. Camargo JL, Zelmanovitz T, Paggi A, Friedman R, Gross JL. Accuracy of conversion formulae for estimation of glycohemoglobin. Scand J Clin Lab Invest. 1998;58(6):521-8. http://dx.doi. org/10.1080/00365519850186337. PMid:9832345.

21. Friedewald WT, Levy RI, Fredrickson DS. Estimation of the concentration of low-density lipoprotein cholesterol in plasma, without use of the preparative ultracentrifuge. Clin Chem. 1972;18(6):499-502. PMid:4337382.
22. Wadén J, Tikkanen H, Forsblom C, Fagerudd J, Pettersson-Fernholm $\mathrm{K}$, Lakka $\mathrm{T}$, et al, and the FinnDiane Study Group. Leisure time physical activity is associated with poor glycemic control in type 1 diabetic women: the FinnDiane study. Diabetes Care. 2005;28(4):777-82. http:// dx.doi.org/10.2337/diacare.28.4.777. PMid:15793172.

23. Salvatoni A, Cardani R, Biasoli R, Salmaso M, De Paoli A, Nespoli L. Physical activity and diabetes. Acta Biomed. 2005;76(Suppl 3):85-8. PMid:16915806.

24. Wadén J, Forsblom C, Thorn LM, Saraheimo $\mathrm{M}$, Rosengård-Bärlund $\mathrm{M}$, Heikkilä O, et al, and the FinnDiane Study Group. Physical activity and diabetes complications in patients with type 1 diabetes: the Finnish Diabetic Nephropathy (FinnDiane) Study. Diabetes Care. 2008;31(2):230-2. http://dx.doi.org/10.2337/dc07-1238. PMid:17959867.

25. Ferreira CL, Ferreira MG. Características epidemiológicas de pacientes diabéticos da rede pública de saúde - análise a partir do sistema HiperDia. Arq Bras Endocrinol Metabol. 2009;53(1):806. http://dx.doi.org/10.1590/ S0004-27302009000100012. PMid:19347189.

26. Marshal A, Bauman A. The International Physical Activity Questionnaire: summary report of the reliability \& validity studies. Document of IPAQ Executive Committee; 2001.

27. Moberg E, Kollind M, Lins PE, Adamson U. Day-to-day variation of insulin sensitivity in patients with type 1 diabetes: role of gender and menstrual cycle. Diabet Med. 1995;12(3):224-8. http://dx.doi. org/10.1111/j.1464-5491.1995. tb00462.x. PMid:7758258.
28. Al Khalifah RA, Suppère $C$, Haidar A, Rabasa-Lhoret R, Ladouceur M, Legault L. Association of aerobic fitness level with exercise-induced hypoglycaemia in Type 1 diabetes. Diabet Med. 2016;n/a. http:// dx.doi.org/10.1111/dme.13070 PMid:26773719.

29. Brazeau AS, Rabasa-Lhoret $R$, Strychar I, Mircescu H. Barriers to physical activity among patients with type 1 diabetes. Diabetes Care. 2008;31(11):2108-9. http:// dx.doi.org/10.2337/dc08-0720. PMid:18689694.

30. Umpierre D, Ribeiro PA, Kramer CK, Leitão CB, Zucatti AT, Azevedo MJ, et al. Physical activity advice only or structured exercise training and association with $\mathrm{HbA} 1 \mathrm{c}$ levels in type 2 diabetes: a systematic review and meta-analysis. JAMA. 2011;305(17):1790-9. http://dx.doi. org/10.1001/jama.2011.576. PMid:21540423.

31. Ramalho AC, Soares S. [The role of exercise in the treatment of type 1 diabetes]. Arq Bras Endocrinol Metabol. 2008;52(2):260-7. PMid:18438536.

32. Bicalho PG, Hallal PC, Gazzinelli A, Knuth AG, VelásquezMeléndez G. Adult physical activity levels and associated factors in rural communities of Minas Gerais State, Brazil. Rev Saude Publica. 2010;44(5):88493. http://dx.doi.org/10.1590/ S0034-89102010005000023. PMid:20676590.

33. Zanchetta LM, Barros MB, César CL, Carandina L, Goldbaum M, Alves MC. Physical inactivity and associated factors in adults, São Paulo, Brazil. Rev Bras Epidemiol. 2010;13(3):38799. http://dx.doi.org/10.1590/ S1415-790X2010000300003. PMid:20857026. 